IZA DP No. 9845

\title{
Psychological Momentum and Gender
}

Danny Cohen-Zada

Alex Krumer

Ze'ev Shtudiner

March 2016 


\title{
Psychological Momentum and Gender
}

\author{
Danny Cohen-Zada \\ Ben-Gurion University of the Negev \\ and IZA
}

Alex Krumer

SEW, University of St. Gallen

\section{Ze'ev Shtudiner}

Ariel University

\section{Discussion Paper No. 9845 \\ March 2016}

\author{
IZA \\ P.O. Box 7240 \\ 53072 Bonn \\ Germany \\ Phone: +49-228-3894-0 \\ Fax: +49-228-3894-180 \\ E-mail: iza@iza.org
}

\begin{abstract}
Any opinions expressed here are those of the author(s) and not those of IZA. Research published in this series may include views on policy, but the institute itself takes no institutional policy positions. The IZA research network is committed to the IZA Guiding Principles of Research Integrity.

The Institute for the Study of Labor (IZA) in Bonn is a local and virtual international research center and a place of communication between science, politics and business. IZA is an independent nonprofit organization supported by Deutsche Post Foundation. The center is associated with the University of Bonn and offers a stimulating research environment through its international network, workshops and conferences, data service, project support, research visits and doctoral program. IZA engages in (i) original and internationally competitive research in all fields of labor economics, (ii) development of policy concepts, and (iii) dissemination of research results and concepts to the interested public.
\end{abstract}

IZA Discussion Papers often represent preliminary work and are circulated to encourage discussion. Citation of such a paper should account for its provisional character. A revised version may be available directly from the author. 


\section{ABSTRACT}

\section{Psychological Momentum and Gender}

We exploit a natural experiment in which two professionals compete in a one-stage contest without strategic motives and where one contestant has a clear exogenous psychological momentum advantage over the other in order to estimate the causal effect of psychological momentum on performance. We find that men's performance is significantly affected by psychological momentum, while women's is not. This result is robust to different specifications and estimation strategies. Our results are in line with evidence in the biological literature that testosterone, which is known to enhance performance of both men and women, commonly increases following victory and decreases following loss only among men. Implications of our findings for contest design are also discussed.

JEL Classification: J16, J24, L83

Keywords: psychological momentum, contest, gender differences, performance

Corresponding author:

Alex Krumer

Swiss Institute for Empirical Economic Research

University of St. Gallen

Varnbüelstrasse 14

$\mathrm{CH}-9000$ St. Gallen

Switzerland

E-mail: alexander.krumer@unisg.ch

\footnotetext{
* The authors thank Sagi Gur, Andrea Ichino, Moshe Justman, Florian Lindner, Ignacio PalaciosHuerta, Oren Rigbi, Bradley Ruffle, Aner Sela, Andrew Yates, Ro'i Zultan, seminars participants at University of St. Gallen and Ski and Labor seminar 2016 for helpful comments. We gratefully acknowledge the help of Elisabetta Fratini and Simon Mares from the International Judo Federation (IJF) for their assistance with the collection of the data. Finally, we thank Hedva Kazin for an excellent research assistance.
} 


\section{Introduction}

The effect of success or failure on subsequent performance has aroused much attention among economists and motivation researchers for quite some time now, with the common perception being that momentum can powerfully affect performance. This can be seen in various situations including political campaigns (Klumpp and Polborn 2006), investment in the stock markets (Fama and French 2012; Asness et al. 2013) and tennis matches (Malueg and Yates 2010).

Two distinct types of momentum are known to exist in the contest literature: strategic momentum and psychological momentum. Strategic momentum is generally generated by strategic incentives inherent in the contest (Mago et al. 2013). To illustrate, Klumpp and Polborn (2006) theoretically showed that in sequential elections between two candidates, the loser of the first district will have a lower incentive to exert costly effort in the second district, thereby yielding an increased probability for the winner of the first district to win again. Psychological momentum, on the other hand, is defined as a bidirectional concept affecting either the probability of success or failure as a function of the outcome of the preceding event (Adler, 1981). To put it more simply, psychological momentum is the tendency of an outcome to be followed by a similar outcome not caused by any strategic incentive of the players.

Identifying the causal effect of psychological momentum on performance involves two main challenges. First, in most multi-stage contests, psychological and strategic momentum coexist, so that isolating the effect of one from the other is not a trivial task. Second, in most settings a player gains a momentum advantage over his opponent by performing better in previous stages of the contest so it is generally an endogenous variable. Moreover, since the player with the momentum advantage is generally the stronger one, a "naïve" approach of correlating momentum and performance will yield an upward biased estimate. This can lead the researcher to conclude that psychological momentum does affect performance while actually it doesn't. Although many attempts have been made to quantify the effect of psychological momentum on performance, most of them have merely adopted such a "naïve" approach (see, for example, Iso-Ahola and Mobily 1980). A notable exception is Malueg and Yates (2010) who investigated tennis matches that were in the form of best-of-three sets between equally skilled players in order to identify the separate effects of strategic and psychological momentum on performance. They found that, as is predicted by strategic momentum theory, the winner of the 
first set has a higher probability to win in the second set, but that contrary to psychological momentum theory, if the match reaches the third set, then the winner of the second set do not have a significantly higher probability to win that set. Based on the latter finding they conclude that psychological momentum does not play a significant role in contests. The laboratory results of Mago et al. (2013) support these findings. Except for these studies, we are not aware of other studies that effectively dealt with the mentioned challenges in estimating the causal effect of psychological momentum. Moreover, there is no such study that deals with gender differences in responding to psychological momentum.

In this paper we fill this gap by estimating the causal effect of psychological momentum on performance in real tournament settings and also by examining whether there are any gender differences in this response. Two special features of our natural experiment setting allow us to overcome the above mentioned challenges in identifying the causal effect of psychological momentum on performance. First, the contest that we use includes only one stage, namely the last stage of a tournament, which eliminates strategic considerations. Second, unlike most settings in which the contestant with the momentum advantage is the stronger one, in our setting he is, on average, similar to, if not weaker than the other contestant in all respects that are relevant to performance. Thus, this unique setting, which turns out to exist in bronze medal fights of professional judo, allows us to obtain a conservative estimate of the causal effect of psychological momentum on performance.

In our contest, both contestants reach the bronze medal fight after winning all their previous fights except for one. However, one contestant reaches this fight after winning his last fight but losing his second-to-last one (hereafter this contestant is referred to as LW), while the other contestant reaches this fight after losing his last fight but winning his second-to-last one (hereafter this contestant is referred to as WL). More specifically, the LW contestant first loses in the quarterfinal and then wins in the repêchage stage against one of the losers of the quarterfinal, while the WL contestant first wins in the quarterfinal stage but then loses in the semifinal. Thus, the LW contestant has a clear psychological momentum advantage over the WL contestant since he reaches the fight after winning while his opponent reaches the fight after losing. Furthermore, in this scenario we expect the WL to be similar to if not better than the LW contestant who has the momentum advantage. This is because, although both contestants lost exactly one fight, the WL contestant lost in a later stage of the tournament in which the contestants are on average 
stronger than those in the quarterfinal. Also, he won against a contestant who is, on average, better, relative to the one won by the LW contestant. Thus, the contrast between the LW contestants who reach the bronze medal fight from the repêchage stage, the "treatment group", and their counterparts, the WL contestants who reach the bronze medal fight from the semifinal, the "control group", provides a conservative setting for estimating the causal effect of psychological momentum.

Our results show that based on a cross-section of 2,140 men's and 1,484 women's fights from eight major annual judo events, having a psychological momentum advantage significantly increases the winning probability in men's (by about 18 percentage points) but not in women's fights. Moreover, we obtain similar results when applying a fixed-effect estimation that analyzes how the performance of the same pair of judokas is affected by varied momentum statuses in different tournaments. These findings imply that if there are two players who are ex-ante symmetric, the contestant with the psychological momentum advantage has a winning probability of about $68 \%$, which is more than twice his opponent's probability.

In addition, although the data are biased against finding that psychological momentum affects performance, we nevertheless attempt to tease out the effect of selection in order to obtain unbiased estimates. Obviously, selection concerns stem from the fact that prior to the bronze medal fight, the two contestants won and lost in different stages of the tournament, where, on average, the LW contestant won and lost against weaker contestants relative to the WL contestant. Consequently, we expect the LW contestant to be, on average, weaker than the WL one. However, we argue that, conditional that in the previous stages of the tournament both the WL and LW contestants lost to same quality contestants and also won against same quality contestants, they should be, on average, equal. For example, if both the WL and LW contestants lost to finalists, but the LW contestant was randomized to compete against a finalist in the quarterfinal stage, while the WL one only in the semifinal, and they also won against contestants of similar quality, then there is no reason to assume that the WL contestant is stronger than the LW counterpart. Obviously, it is only randomization that allowed the WL contestant to reach a higher stage in the tournament. In other words, conditional on the rankings of the contestants that each of the LW and WL contestants won and lost against, these two contestants are expected to be, on average, similar. Thus, by controlling for these rankings we are able to more cleanly identify the causal effect of the psychological momentum advantage on performance. As 
expected, the results of these specifications indeed indicate that controlling for selection increases the psychological momentum effect among men while a momentum effect is still not found among women.

Interestingly, our finding that psychological momentum positively affects performance among men but not among women is consistent with the biological literature on the effect of innate testosterone levels on performance. This literature has widely shown that while higher testosterone levels enhance performance of both men and women (ACSM, 2006), it commonly increases following victory and decreases following loss only among men (Booth et al., 1989; Elias, 1981; Gladue et al., 1989; Mazur et al., 1992, Bateup et al., 2002, Edwards and Kurlander, 2010; Edwards et al., 2006; among many others). ${ }^{1}$ Thus, it is only among men that previous winnings lead to increased levels of testosterone, which in turn increases the likelihood of future wins, while previous losses lead to decreased levels of testosterone, which in turn increases the chances of further losses. ${ }^{2}$ In fact, it has been documented that post-competition testosterone increases are positively associated with increasing aggression, willingness to compete and motivation to win (Suay et al., 1999; Carre et al., 2010; Carre and McCormick, 2008). Furthermore, Salvador et al. (2003) provide direct evidence that judokas with pre-contest higher levels of testosterone obtained better results in future matches. ${ }^{3}$ Thus, it is plausible to expect that among men the LW contestants who reach the bronze medal fight after winning would have higher levels of testosterone relative to the WL contestants, which would help them win.

Since it has been shown that testosterone increases for men after different types of success and not only after winning in sports, it is likely that the mediating role of testosterone in reinforcing future success may extend to other areas. ${ }^{4}$ In fact, because testosterone has also been shown to be positively associated with increased risk-taking in economic domains (Stanton et al.,

\footnotetext{
${ }^{1}$ For additional details on the mediating effect of testosterone in creating a positive momentum effect see the comprehensive review of Wood and Stanton (2012).

${ }^{2}$ Evidence for this mechanism through which testosterone leads to a positive momentum effect among males is found in Mazur (1985). In addition, such evidence is also provided in animal studies (Trainor et al., 2004; Oyegbile and Marler, 2005). For example, experimentally-manipulated post-victory increases in testosterone among male rodents facilitated increased victory in subsequent encounters, whereas the experience of victory alone did not (Trainor et al., 2004). Similarly, Oyegbile and Marler (2005) have found among male mice that post victory endogenous testosterone increases have a reinforcing effect on future victories.

${ }^{3}$ Because testosterone has an important effect on performance, exogenous testosterone has been banned by most international sports federations. Also, since 1976, its use has been banned by the International Olympic Committee.

${ }^{4}$ For example, McCaul et al. (1992), conducted two experiments in which male college students either won or lost $\$ 5$ on a task controlled entirely by chance and found that the winners exhibited significantly higher testosterone levels than the losers.
} 
2011; Van Honk et al., 2004; Mazur, 1995), it may induce positive momentum effects in financial and other economic markets as well. Interestingly, Nobel Prize Laureate Eugene Fama referred to momentum as the biggest challenge to his theory of financial market efficiency (see also Fama and French 2012; Asness et al. 2013). ${ }^{5}$ Indeed, several papers find a positive association among male traders between testosterone levels and higher profits in financial markets (Coates and Herbert 2008; Coates et al., 2009). Recently, Cueva et al. (2015) provided evidence that increases in testosterone lead to greater optimism and risk taking among men. The authors thus claim that "...testosterone may help to sustain the upward momentum of a bull market in which high profits fuel optimism... and lead to further risk taking” (p. 8).

It is worth noting that a recent experimental study conducted by Eckel and Füllbrunn (2015) reports an inverse relationship between the magnitude of price bubbles and the frequency of female traders in the market. The authors mention that one of the possible explanations for the collapse of the housing bubble in 2008 was that female traders' representation in the Wall Street was only ten percent. Similarly, Coates et al. (2010) claim that there are grounds to assume that women are less exposed to the effect of testosterone when it comes to financial risk taking (see also Coates, 2012). Such an effect may lead male traders, driven by increase in testosterone due to a successful investment, to take exaggerated risks, which, in turn, create price bubbles. Thus, by increasing the share of women among traders, it is possible to stabilize the financial markets since women have a very different biology with less dramatic shifts in testosterone levels, which can make them less prone to the momentum effect. This argument is consistent with our results that momentum effects are generated only among men since only among them testosterone levels increase after success. ${ }^{6}$

Our finding on a positive momentum effect also has important implications for contest design. First, a contest designer that ignores the existence of psychological momentum may

\footnotetext{
${ }^{5}$ From https://www.minneapolisfed.org/publications/the-region/interview-with-eugene-fama (accessed January, 25, 2016).

${ }^{6}$ The linkage between gender, testosterone and financial performance has attracted much attention in the media as well. For example, an article in the New York Times asks whether the excessive risk-taking on Wall Street is fostered by testosterone-fueled dominant males leading the top firms, thus inflating the housing and securitization bubbles (From http://opinionator.blogs.nytimes.com/2010/04/01/does-wall-street-need-an-estrogen-injection/?dbk). Similarly, the popular British newspaper “The Daily Telegraph” quoted one of the financial trading websites saying: "Think like a woman to succeed in trading” (From http://www.telegraph.co.uk/women/womensbusiness/9690599/Boys-will-be-boys-Why-women-make-better-traders-than-men.html, accessed January 25th, 2016).
} 
mistakenly consider his contest to be fair, which is not the case as it gives one player a much higher probability to win. Moreover, ignoring psychological effects between two symmetric players may also disrupt the competitive balance and thus the total expected effort. This is because, as predicted by tournament theory, the total amount of effort exerted in the course of a tournament is highest when the contestants are homogeneous (Lazear and Rosen, 1981; Rosen, 1986). Thus, a contest designer who creates asymmetry by giving one contestant a psychological advantage over his opponent decreases the total expected effort. To illustrate how taking psychological effects into account can make the contest fairer we present a different contest design that solves the asymmetry stemming from psychological momentum. This alternative contest design will also increase the competitive balance and thus the total expected effort.

Finally, the paper is also applicable to the literature on the importance of reference points. In their pioneering study, Kahneman and Tversky (1979) showed that reference points may affect decision making. Apesteguia and Palacios-Huerta (2010) referred to the score at the time a player had to kick a ball in soccer penalty shootouts as the reference point, and found that the first kicking team had a significant margin of 21 percentage points over the second kicking team. This finding was challenged by Kocher et al. (2012) who, using a larger sample of soccer shootouts, found that the first-kicking team's winning percentage was not significantly different from $50 \%$. In our setting, whether a contestant arrives to the bronze medal fight after winning or losing would also seem to serve as a reference point. Thus, if reference points are not important we would expect that, since the contestant with the psychological momentum advantage is similar if not weaker than the other one, he should have a similar if not lower probability to win the next fight. However, in line with the literature on testosterone, our results indicate that at least for men, the reference point does crucially affect the probability of each contestant to win the fight.

The rest of the paper is organized as follows: Section 2 describes the natural experiment. The data are presented in Section 3. Section 4 presents the estimation strategy and results. Finally, in Section 5 we offer concluding remarks. 


\section{Description of the natural experiment}

In Figure 1 we describe the structure of the judo tournament from the quarterfinal stage and illustrate the uniqueness of this setting. In order to reach this stage a contestant has to win all his fights. The eight contestants who reach the quarterfinal stage compete in pair-wise matches (fights), where each match is a one stage contest. Without loss of generality, suppose that contestants 1, 3, 5 and 7 won in the quarterfinal stage and therefore qualified to the semifinal stage where they compete for the right to qualify for the final. ${ }^{7}$ The losers of the quarterfinals, namely contestants 2, 4, 6 and 8 compete in the repêchage stage. Each of the winners of this stage, suppose contestants 2 and 6, will compete one last time against one of the losers of the semifinals, suppose players 3 and 5 . Each of the winners in that stage, which is our stage of interest, receives a bronze medal (notice that two contestants receive a bronze medal). We can see that all contestants that compete for the bronze medal won all their previous matches except for one. However, contestants 2 and 6 reached this fight after winning their last fight but losing their second-to-last fight (LW), while players 3 and 5 after losing their last fight but winning their second-to-last fight (WL). Thus, the LW contestants, 2 and 6, have a clear psychological momentum advantage over the WL contestants, 3 and 5, as they compete immediately after winning while their counterparts compete immediately after losing.

In addition, it is easy to see that the momentum advantage of contestants 2 and 6 does not stem from any superior performance in the previous stages of the tournament relative to the losers of the semifinal. In fact, we expect the WL contestants, 3 and 5, to be similar to, if not better than, contestants 2 and 6. For one thing, they lost in a later stage of the tournament (the semifinals) relative to players 2 and 6 who lost in the quarter final. Thus, on average, they lost to stronger contestants. To illustrate, in the second bronze medal fight, contestant 6 (LW) competes against contestant $3(\mathrm{WL})$, where the former has a momentum advantage. Although both of them have lost exactly one match, we expect contestant 3 to be, on average, stronger, as he lost in the semifinals to a finalist (contestant 1) while contestant 6 lost in the quarterfinal to contestant 5 who is a weaker contestant who only competes for a bronze medal. The fact that the contestants in the semifinal are, on average, stronger than the contestants in the quarter final is also evident from the average ranking of the contestants in each stage, which we report in Figure 1. The

\footnotetext{
${ }^{7}$ For more basic rules of judo competitions see Balafoutas et al. (2012).
} 
average ranking index of the contestants in the semifinal stage is 3.08 and 2.68, for men and women respectively, while the corresponding values of this index for the contestants in the quarterfinal stage are 3.53 and 3.29 (a higher ranking index implies a weaker contestant). ${ }^{8}$

Another reason why the WL contestants, 3 and 5, are expected to be stronger than the LW contestants is that, on average, they also won against a better contestant. They won in the quarterfinal, while the LW contestants won in the repêchage stage. Obviously, the contestants in the repêchage stage are, on average, weaker because they are the losers of the quarterfinal stage. As reported in Figure 1, while the average ranking index of the contestants in the quarterfinal stage is 3.53 for men and 3.29 for women, the corresponding numbers for the contestants in the repêchage stage are 3.98 and 3.92, for men and women, respectively. These rankings indicate that, on average, the WL contestants won against better contestants relative to their LW counterparts.

In summary, as the WL contestants won and lost against better contestants they are expected to be at least equal if not stronger than their LW counterparts. Indeed, while the average ranking index of the contestants who reach the bronze medal fight from the semifinals is 3.39 and 3.16, for men and women, respectively, the corresponding numbers for the contestants who reach the bronze medal fight from the repêchage stage is 3.89 and 3.68, for men and women, respectively. These numbers provide direct evidence that the WL contestants are, on average, stronger than their LW counterparts. In addition, in $62 \%$ of the bronze medal fights, the favorite (higher ranked) contestant reached this fight from the semifinal (WL) and not from the repêchage (LW). For all the mentioned reasons, a simple contrast between the contestants who reached the bronze medal fight from the repêchage stage (LW), the "treatment group", and their counterparts who reached the bronze medal fight from the semifinal (WL), the "control group", provides a lower bound estimate of the causal effect of psychological momentum.

In order to evaluate the exact causal effect and not a lower bound, we should attempt to compare two contestants who are, on average, identical. We argue that if both the WL and LW contestants lost to same quality contestants and won against same quality contestants then they should be, on average, equal. The reason is that they performed exactly the same in the tournament. Obviously, in this case, the only difference between them is the timing of their loss,

\footnotetext{
${ }^{8}$ In section 3.2 we will define the ranking index explicitly.
} 
which is only due to randomization. To illustrate this, we can see in Figure 1 that in the first bronze medal fight contestant 2 (LW) competes against contestant 5 (WL). In this specific case contestant 2 did not lose previously to a weaker contestant relative to contestant 5 . Instead, both of them lost to contestants who reached the final. It is only "unlucky" randomization that caused contestant 2 to lose at an earlier stage in the tournament. If he were randomized to first compete against contestant 4 and only then against contestant 1 he would have probably reached the semifinal exactly like contestant 5 . In this case, if contestants 2 and 5 also won against similar contestants (i.e, if contestants 4 and 6 are of equal quality), we have no reason to expect that contestant 2 is weaker than contestant 5 , as both of them lost exactly one match and also won and lost to similar quality contestants.

Thus, by controlling for the rankings of the contestants that the LW and WL players won and lost to in their previous two fights, we are able to identify more cleanly the causal effect of psychological momentum advantage on performance. ${ }^{9}$ In the first bronze medal fight between contestants 2 and 5, for example, the variable LWLOST will report the ranking index of contestant 1, and the variable LWWIN the ranking index of contestant 4. Similarly, the variable WLLOST the ranking index of contestant 7 and the variable WLWIN the ranking index of contestant 6. We argue that conditional on these four mentioned controls, psychological momentum advantage is as good as randomly assigned. This unique setting in which both contestants have the same previous performance in the tournament, conditional on the four mentioned controls, will allow us to obtain consistent estimates of whether or not psychological momentum affects the probability to win a fight and whether or not this effect differs between genders.

\section{Data and variables}

\subsection{Data}

In order to estimate the causal effect of a psychological momentum advantage on performance we took two different approaches. The first is to use a cross-section analysis while the second is to use a fixed-effect estimation that exploits a panel dataset to analyze the

\footnotetext{
${ }^{9}$ We do not need to control for the ranking of the contestants they won against before the quarter final, because until this stage the contest is perfectly symmetric.
} 
performance of the same pair of judokas in different tournaments. For our first approach we collected data on all judo fights that took place in the eight major annual judo events during the period between August 2010-August 2013, namely the World Championships, the Olympic Games (there is no World Championship in the year of the Olympic Games), and the Masters and Grand Slam Tournaments (Dataset A). The data include three World Championships (Japan in 2010, France in 2011 and Brazil in 2013), the 2012 London Olympics Games, a Masters Tournament in Russia that was held in 2013, and three Grand Slam Tournaments in 2013 (Azerbaijan, France and Russia). Only Masters and Grand Slam Tournaments that took place in 2013 are represented in our data since previous to that year there were no bronze medal fights in these tournaments. It should also be mentioned that we chose to start collecting the data from August 2010, almost one and a half years after the release of the first ranking list by the International Judo Federation (January 2009), because a large amount of information was missing concerning the competitors’ current ranking for the 2009 World Championships.

For every fight, information was available regarding the names of the judokas, previous head-to-head outcomes between the judokas, their weight category and their world ranking prior to the beginning of the tournament. This ranking takes into account the athletes' best results over the past 24 months and is used as a measure of their abilities. ${ }^{10}$ All data were collected from the official websites of the International Judo Federation. ${ }^{11}$ In all, the data covered 2,451 men's and 1,647 women's fights in seven men's and seven women's weight categories. Unfortunately, for some fights, information was missing about the competitors' current ranking (290 men's and 153 women's fights). In addition, in 22 men's and 12 women's fights, one of the judokas did not turn up due to injury. ${ }^{12}$ Eliminating all these problematic matches left a total of 2,140 men's and 1,484 women’s fights.

\footnotetext{
${ }^{10}$ The ranking of each judoka is determined according to the number of points he received in the last two years, where different tournaments grant a different number of points according to the importance of the tournament. The points for each tournament count $100 \%$ only in the first 12 months after the tournament. Then, after 12 months and up to 24 months, the number of points granted by each tournament is reduced to $50 \%$. Points are not accounted for at all after 24 months. For more details see http://www.intjudo.eu/fo-Rankingir. The data on weekly rankings were received from Elisabetta Fratini from the IT Department of the International Judo Federation (IJF).

${ }^{11}$ The data on all judo fights were downloaded from the IJF web site at http://intjudo.eu/Galery/cikk1768/ cikk1774-Result_mutat. The data of all head-to-head fights were downloaded from the Judobase web site at http://www.judobase.org/\#/dashboard (accessed July, 17, 2014)

${ }^{12}$ There is no statistical gender difference between the injury ratios ( $\mathrm{p}$-val $=0.29$ )
} 
For our second approach, we selected from dataset A only the fights in the bronze medal round (104 men's and 109 women's different pairs) and for each of these pairs we collected the history of all their previous fights in all possible international tournaments that took place since the release of the first ranking list by the International Judo Federation (January 2009) up to the date of the last tournament that was included in our data (August 2013). In all, this new data covered 234 men's and 241 women's fights. However, for some fights, information was missing about the competitors' current ranking (9 men's and 10 women's fights), which left us with a total of 225 men’s and 231 women’s fights.

\subsection{Variables}

\subsubsection{Dataset A}

For dataset A, we first define for each fight the higher-ranked judoka as the favorite and the lower-ranked one as the underdog. Then, we estimate the probability that the favorite will win the fight. Accordingly, we assign the dependent variable a value of 1 if the favorite judoka won and zero otherwise. In Table 1 we can see that favorites won in $70 \%$ of men's and $69.4 \%$ of women's fights.

Our key independent variables are measures for momentum status. In dataset A we use two momentum variables. The first one, $F M A_{i j w t}$, indicates whether the favorite contestant $i$ has a psychological momentum advantage over the underdog contestant $j$, given the weight category $w$ and the type of tournament $t$. This variable gets the value of one only if the favorite contestant won his last fight while the underdog contestant lost his last fight, and zero otherwise. Similarly, the variable $U M A_{i j w t}$ gets the value of 1 only if the underdog contestant won his last fight while the favorite contestant lost his last fight, and zero otherwise.

The probability of the favorite to win against the underdog is obviously a function of their relative strength. We use two different measures in order to control for the relative strength of the two contestants. The first one, RANKDIFF $i j w$, is defined as $\log _{2}\left(R a n k F_{i w t}\right)-\log _{2}\left(R a n k U_{j w t}\right)$, where $R a n k F_{i w t}$ and $R a n k U_{j w t}$ are the most current world ranking of the favorite and the underdog, respectively. The main advantage of this measure is that the differences in players' quality are not linear but rather grow at an increasing rate as we 
move up the ranking. This implies that a difference of one position in the ranking list corresponds to a smaller difference in quality if the judokas are at the bottom of the list, but to a more substantial difference when we compare the top contestants (see also Passerman 2010; Krumer 2014). Table 1 shows that the mean value of this measure is negative owing to the fact that the favorite is associated with a lower ranking number. The second measure that may provide information about the differences in the abilities of the two contestants is the difference in head-to-head victories prior to the respective fight. Thus, for each fight we calculate the number of head-to-head victories in favor of the favorite. This variable is measured as the difference between the numbers of fights that the favorite and the underdog won in previous head-to-head fights against each other.

Based on Krumer (2014), who found a significant influence of having a home advantage in professional judo for both genders, we also include in our estimations two dummy variables indicating whether each judoka has this advantage. Thus, the variable that indicates that the favorite has a home advantage gets the value of one if the favorite competes at home while the underdog does not. Similarly, the variable that indicates that the underdog has a home advantage gets the value of one if he competes at home while the favorite does not. We also include control dummies for each weight, type of tournament, and stage in tournament categories. The descriptive statistics are presented in Table 1.

\subsubsection{Dataset B}

In this dataset we have panel data that we collected on each pair of judokas in different tournaments during the period between January 2009 and August 2013. Therefore, since the same judoka can be the favorite in one tournament but the underdog in another, we cannot use the "favorite-underdog" terminology. To overcome this problem, we denote the judoka whose name appears first in alphabetical order as judoka $i$, whereas the other judoka as judoka $j$. When using this database we estimate the probability that judoka $i$ wins the match. Thus, the dependent variable is assigned a value of 1 if judoka $i$ won the match and zero otherwise. In Table 2 we can see that judoka $i$ won in $48.9 \%$ of men's and $48 \%$ of women's fights.

In this approach, the momentum variable, $M I_{i j w t}$ can get three possible values: one if judoka $i$ won his last fight in tournament $t$, while judoka $j$ lost his last fight; a value of zero if neither of the players lost any previous fight in the tournament or both of them lost their last 
fight; and a value of minus one if judoka $i$ lost his last fight in the tournament while judoka $j$ won his last fight. We provide summary statistics for dataset B in Table 2.

\section{Estimation strategy and results}

We begin by estimating, separately for each gender, a logit model of the probability of the favorite judoka to defeat the underdog as a function of two variables indicating whether each player has or doesn't have a momentum advantage over the other. In this estimation we utilize a cross-section of all judo fights and not only those of the bronze medal. Our set of controls includes our measure for the relative strength of the players, $R A N K D I F F_{i j w t}$, dummy variables for whether each of them has a home advantage, and the past head-to-head favorite's advantage (number of favorite's wins minus number of favorite's losses). We also estimate a specification in which we add fixed effects for each weight category and each tournament type. Formally, this specification takes the following form:

$$
\log \left(\frac{\pi_{i j w t}}{1-\pi_{i j w t}}\right)=\alpha_{w}+\alpha_{t}+\beta_{1} \cdot F M A_{i j w t}+\beta_{2} \cdot U M A_{i j w t}+\beta_{3} \cdot X_{i j t}+\varepsilon_{i j w t}
$$

where the dependent variable is the probability of the favorite player $i$ to defeat the underdog player $j$, given the weight category $w$ and the type of tournament $t$, and $X_{i j t}$ is a set of controls indicating the relative advantage of the favorite in several dimensions such as rankings, past head-to-head fights and home advantage. As described previously, the first momentum variable, $F M A_{i j w t}$, gets the value of one only if the favorite player won his last fight (LW) while the underdog player lost his last fight (WL), and zero otherwise. Similarly, the variable $U M A_{i j w t}$ gets the value of 1 only if the underdog player is the one who won his last fight (LW) while the favorite player lost his last fight (WL), and zero otherwise. These two momentum variables can appear together in the estimation because in all the fights except those for the bronze medal, none of the judokas has a momentum advantage over the other as they compete against each other after both of them won all their previous fights. Thus, except for the fights for the bronze medal, these two momentum variables get a value of zero.

In Table 3, Panel A and Panel B report average marginal effects for men and women, respectively. Robust standard errors appear in parentheses. Columns 1 and 2 report the results for the above specification with and without weight and tournament fixed effects. The results for 
men indicate that in both columns the coefficient of the variable $F M A_{i j w t}$ is insignificant, which implies that having a momentum advantage by the favorite relative to neither of the contestants having a momentum advantage does not affect the probability of the favorite to win the fight. However, both estimations indicate that if the underdog has a psychological momentum advantage (relative to neither of the contestants having a momentum advantage), it substantially and significantly decreases the probability of the favorite to win the fight by between 13.8 and 13.1 percentage points. In stark contrast, the results for women indicate that neither momentum variables is significant. ${ }^{13}$

We also add to our basic specifications fixed effects for each stage in the tournament and estimate the following specification:

(2) $\log \left(\frac{\pi_{i j w s t}}{1-\pi_{i j w s t}}\right)=\alpha_{w}+\alpha_{s}+\alpha_{t}+\beta_{1} \cdot F M A_{i j w s t}+\beta_{3} \cdot X_{i j t}+\varepsilon_{i j w s t}$,

where the set of controls for each stage in the tournament, $\alpha_{s}$, includes a dummy variable, $B M$, indicating whether the fight is for a bronze medal. Because this variable equals the sum of the two momentum variables, FMA and UMA, to avoid multicollinearity we omit the variable $U M A$ from the estimation. The results of this specification are reported in Column 3 of Table 3, where the coefficient of the bronze medal dummy should be interpreted as the effect of the underdog having a momentum advantage (relative to neither of the contestants having a momentum advantage) on the probability of the favorite to win the fight, and the coefficient of FMA should be interpreted as the effect of the favorite having a momentum advantage relative to the underdog having a momentum advantage on the probability of the favorite to win the fight. In other words, the coefficient of the variable FMA reflects the increased probability of the favorite to win the fight due to being the $\mathrm{LW}$ contestant relative to being the WL contestant. The results for men show that the favorite having a momentum advantage (relative to the underdog having a momentum advantage) significantly and substantially increases the probability of the favorite to win the fight by 17.8 percentage points. Again, the momentum variable is found to be insignificant for women.

\footnotetext{
${ }^{13}$ A possible concern is that our finding is driven by the fact that men's ranking may be either more or less accurate than women's ranking. To rule this possibility out we tested whether these rankings indeed have different effects on winning probabilities between the genders and found no differential effects. The results are available upon request.
} 
Next, we extract from the above-mentioned cross-section sample only the fights for the bronze medal and estimate for each gender to what extent the probability of the favorite to win the fight is affected by whether he and not his opponent has a momentum advantage. The results, both with and without fixed effects for each weight and tournament type categories, are reported in Columns 4 and 5 of Table 3, respectively. The results in Column 4 show that when the favorite has a momentum advantage his probability to win the fight significantly and substantially increases by 17.6 percent. When weight and tournament type fixed effects are added to the equation (see Column 5), the effect of the momentum variable becomes slightly smaller but still significant at the $10 \%$ level. Among women, the results in both columns indicate that when the favorite has a momentum advantage there is no significant effect on the probability to win the fight.

The causal interpretation of these estimates relies on the assumption that when the favorite does not have the momentum advantage (i.e, when he is the WL contestant), he is similar to, if not stronger, relative to when he does have a momentum advantage (i.e, when he is the LW contestant). In addition, when the favorite has a momentum advantage, the underdog is similar to, if not stronger, relative to when the favorite does not have a momentum advantage. In order to test the validity of this assumption we run (separately for men and women) a regression of the difference between the ranking measure of the favorite and the ranking measure of the underdog, $R A N K D I F F_{i j w t}$, on the variable that indicates whether the favorite has a momentum advantage. The results, reported in Columns 1 and 2 of Table 4, indicate that the favorite having a momentum advantage is positively associated with the ranking difference between the favorite and the underdog (for men it has a p-value of 0.12). Thus, if at all, when the favorite has a momentum advantage he is weaker and not stronger relative to when he doesn't have a momentum advantage. In addition, we also checked whether the momentum status is correlated with the previous head-to-head victories in favor of the favorite and with one of the contestants having a home advantage, and find no evidence for such correlation. In summary, the results in this table show that, if at all, selection works against finding that momentum has a positive effect on performance since the fights in which the favorite has a momentum advantage are more balanced with regard to the gap between the rankings of the players.

As mentioned in section 2, the favorite contestant is expected to be, on average, stronger, and the underdog, on average, weaker, when the favorite reaches the bronze medal fight from the 
semifinal (WL) and the underdog from the repêchage stage (LW) relative to when the favorite reaches it from the repêchage stage (LW) and the underdog from the semifinals (WL). For this reason, the above estimations provide a lower bound estimate of the causal effect of psychological momentum advantage on performance. In order to estimate the exact causal effect we should compare two contestants who are, on average, identical. We argue that if both the WL and LW contestants lost to similar contestants and also won against similar contestants then they should be, on average, similar, as they performed exactly the same in the tournament. Obviously, the only difference between them is the timing of their loss, which is only due to randomization. That is, it is only "unlucky" randomization that caused the LW contestant to lose in an earlier stage of the tournament. If he were randomized to meet exactly the same contestants but only in an opposite order, he would have probably reached the semifinal like the WL contestant. Thus, by controlling for the four variables that indicate the ranking indexes of the contestants that the favorite and underdog won and lost to in their two previous fights, we are able to tease out the selection effects. Econometrically, we argue that, conditional on these four variables, the psychological momentum variable is as good as randomly assigned. Thus, we estimate the probability of the favorite to win the fight while adding to equation (2) the four aforementioned variables. Formally, we estimate the following equation:

$$
\begin{aligned}
& \log \left(\frac{\pi_{i j w s t}}{1-\pi_{i j w s t}}\right)=\alpha_{w}+\alpha_{s}+\alpha_{t}+\beta_{1} \cdot F M A_{i j w s t}+\beta_{3} \cdot X_{i j t}+\gamma_{1} \cdot \log _{2}(\text { FavWinRank })+ \\
& +\gamma_{2} \cdot \log _{2}(\text { FavLossRank })+\gamma_{3} \cdot \log _{2}(\text { UndWinRank })+\gamma_{4} \cdot \log _{2}(\text { UndLossRank })+\varepsilon_{i j w s t},
\end{aligned}
$$

The results, reported in Columns 6 and 7 of Table 3, show that, as expected, the estimated effect for men becomes even larger and more significant when we control for selection, and the results for women remain insignificant. ${ }^{14}$

One concern with the previous estimations is that the WL and LW contestants reach the bronze medal fight after each of them passed several fights and thus may be not equally tired. For example, since the WL contestant competed in his last fight against a finalist, while the LW contestant competed in the repêchage stage against a much weaker contestant (one of the losers of the quarter final), it is possible that the WL contestant may be more tired. Fortunately, in all

\footnotetext{
14 The reason for the difference in the number of observations between Columns 4-5 and Columns 6-7 is that for several fights we had missing values in the four variables indicating the ranks of the contestants that the favorite and underdog won and lost to in the previous stages of the tournament.
} 
the tournaments except for the World Championship and the Olympic Games there is a long break of two hours before the start of the fights for the medals. ${ }^{15}$ Thus, by including in the estimation only the tournaments with the long break we are able to rule out the possibility that our results are driven by unequal tiredness of the two players. The results of this estimation, reported in Column 8, again indicate a significant positive momentum effect for men but not for women.

Next, for each specification mentioned above, we test whether, as the biological literature on testosterone predicts, the coefficients of the momentum variable in the regression for men is larger relative to in the regression for women. The p-value of the test is reported in Panel C of Table 3. The results show that in most specifications we reject the hypothesis that men and women respond similarly to psychological momentum at the $5 \%$ significance level and in the other specifications we reject it at the $10 \%$ level.

Finally, we take each judoka pair that competed in the bronze medal fights and create a panel dataset that includes information on all their previous fights that took place between January 2009 and August 2013. Each fight includes information on the ranking and momentum status of each judoka, which of the judokas won the fight, whether either of them had a home advantage, the stage in the tournament in which the fight took place, the type of tournament, and whether it is a men's or a women's fight. This dataset allows us to use a fixed-effect estimation in order to examine, for a given pair of judokas, to what extent the probability of the judoka whose name appears first in alphabetical order (henceforth referred to as judoka $i$ ) to defeat the other judoka (henceforth referred to as judoka $j$ ) is a function of their momentum status. In this specification, our momentum variable, $M I_{i j t}$, can get three possible values: a value of one if judoka $i$ won his last fight in the tournament while judoka $j$ lost his last fight; a value of zero if neither of the players lost any previous fight in the tournament or both of them lost their last fight; and a value of minus one if judoka $i$ lost his last fight while judoka $j$ won his last fight. Because each pair of judokas competed several times in different tournaments, it is probable that in one tournament judoka $i$ was ranked higher while in another tournament judoka $j$ was actually the favorite. Our basic specification with this dataset takes the following form:

15 The length of each fight is five minutes and the protocol requires that each contestant should rest at least ten minutes between the fights. We would like to thank Sagi Gur, the CEO of the Israeli Judo Federation for providing us with this information. 
(4) $\pi_{i j t}=\alpha_{i j}+\beta_{1} \cdot M I_{i j t}+\beta_{3} \cdot X_{i j t}+\varepsilon_{i j t}$,

where the dependent variable is the probability of player $i$ to defeat player $j$ in tournament $t$, and $X_{i j t}$ is a set of controls indicating the relative advantage of the player whose name appears first in alphabetical order in ranking and home advantage. The results for men are presented in Column 1 of Table 5 (robust standard errors are reported in parentheses), and indicate that a unit increase in the momentum index increases the probability of player $i$ to defeat player $j$ significantly and substantially by more than 17 percentage points. Next, we add to equation (4) fixed effects for each stage in the tournament and each tournament type. We are unable to add weight fixed effects because the weight category does not vary for a given pair of judokas (most judokas always compete in the same weight category in different tournaments). This specification takes the following form:

(5) $\pi_{i j s t}=\alpha_{i j}+\alpha_{s}+\alpha_{t}+\beta_{1} \cdot M I_{i j w s t}+\beta_{3} \cdot X_{i j t}+\varepsilon_{i j s t}$,

where the set of stage fixed effects, $\alpha_{s}$, also includes a dummy variable, $B M$, indicating whether the fight is for a bronze medal. In this specification the effect of having a momentum advantage by player $i$ (relative to having a momentum advantage by player $j$ ) on the probability of player $i$ to win the fight is $2 \beta_{1}$. The results for men are reported in Column 2 . They indicate that player $i$ having a momentum advantage (relative to none of the players having a momentum advantage) substantially and significantly increases his probability to win the fight by about 19 percentage points, which is a very large effect. To illustrate, while the probability of each of two equal players without a psychological momentum advantage to win the fight is $50 \%$, if one of them has a momentum advantage his probability to win increases to $69 \%$, which is more than twice the probability of the other player to win (69\% relative to $31 \%$ ). Similar to other specifications, among women, the momentum variable is insignificant.

In our next specification, we add to the equation the past head-to-head victories in favor of player $i$. Since in our previous specification (equation 5) none of the stage category fixed effects or the type of tournament fixed effects was found to be significant or close to significant, we estimate this specification without them. The results show that controlling for the past head-to- 
head variable reduces the estimate for the momentum effect by almost half its size but it still remains substantial and significant at the 6.1 percent significance level. ${ }^{16}$ In Columns 4-6 we report similar results for women, which, once again, indicate that the momentum variable is insignificant. Taken together, the results of all our different estimation strategies provide strong evidence that having a psychological momentum advantage has a substantial and significant effect on the probability to win a fight among men but not among women.

\section{Concluding Remarks}

Nature seldom creates conditions that make it possible to observe a clear view of the causal effect of psychological momentum on performance, mostly because in most cases it is too complicated to disentangle the effect of psychological momentum from that of strategic momentum. Moreover, having a momentum advantage is generally an endogenous variable and teasing out the effect of selection is quite challenging. The natural experiment we have studied overcomes these difficulties and thus provides a rare opportunity to clearly observe the effect of psychological momentum on the performance of high profile agents in high stake situations in a real tournament setting.

Our results support the hypothesis that a psychological momentum advantage significantly and substantially affects performance among men but not among women. This finding, which is robust to different specifications and estimation strategies, is consistent with extensive biological literature on the role of testosterone in reinforcing future winning. According to this literature, men's testosterone endogenously increases following victory and decreases following loss, which in turn reinforces the likelihood of future winning by increasing the willingness to compete and to win again. However, women's testosterone levels to not change significantly following victory or loss.

Since it has been shown that testosterone levels increase in men after different types of success and not only after winning in sport, it is likely that the role of testosterone in reinforcing future success may extend to other areas. Hence our findings have implications in many different

\footnotetext{
${ }^{16}$ When fixed effects for each stage category and each tournament type are added to this estimation they only add noise. The results show that none of these fixed effects are even close to being significant at the $10 \%$ level. In addition, except for the head-to-head advantage of player $i$ variable and the differences in the rankings of the players, the momentum variable is the most significant variable in the estimation (p-value $=0.132$ ).
} 
areas. First, in the labor market, an increased frequency of positive feedbacks after successful actions may turn into a positive psychological momentum and thus increase productivity. Similarly, managers should exert efforts to reduce the influence of unsuccessful actions of their workers in order to avoid losses of productivity due to a negative psychological momentum effect. Second, sometimes momentum can create price bubbles in financial markets, because success in a first investment leads among men to increase their willingness to take additional risks and reinvest. Thus, an increased share of women traders in the market might reduce the creation of such bubbles.

Our findings also have important implications for contest design. First, a contest designer who ignores the existence of psychological momentum may consider his contest design to be fair, which is not the case as it gives one player a higher probability to win. To illustrate how psychological effects can effectively be taken into account, we suggest that it might be worthwhile for the contest designer of the judo tournaments to change the design of the bronze medal fights such that the losers of the semifinals (players 3 and 5 in Figure 1) compete against each other in the first bronze medal fight, whereas the winners in the repêchage stage (players 2 and 6 in Figure 1) compete against each other in the second bronze medal fight (see Figure 2). This alternative contest design will make the contest fairer, in the sense that it will eliminate the meaningful advantage that the current design gives the player with the momentum advantage. In addition, it is supposed to increase the competitive balance and thus the total expected efforts.

Finally, one possible direction for future research could be to examine the role of psychological effects in general, including psychological momentum, on performance, especially in male-dominant positions such as stockbrokers, high-profile managers, politicians and military force commanders. 


\section{References}

Adler, Peter. 1981. Momentum: "A Theory of Social Action". Beverly Hills, CA: Sage.

American College of Sports Medicine (ACSM). 2006. "Position Statement: Senate Hearing on the Abuse of Anabolic Steroids and their precursors by adolescent athletes".

Apesteguia, Jose and Ignacio Palacios-Huerta. 2010. "Psychological Pressure in Competitive Environments: Evidence from a Randomized Natural Experiment." The American Economic Review. 100: 2548-2564.

Asness, Clifford, Tobias Moskowitz and Lasse Heje Pedersen. 2013. "Value and Momentum Everywhere." The Journal of Finance. 68 (3): 929-985.

Balafoutas, Lukas, Florian Lindner and Matthias Sutter. 2012. "Sabotage in Tournaments: Evidence from a Natural Experiment." Kyklos, 65 (4): 425-441.

Bateup, Helen S., Alan Booth, Elizabeth A. Shirtcliff and Douglas A. Granger. 2002. "Testosterone, Cortisol, and Women's Competition." Evolution and Human Behavior. 23(3): 181-192.

Booth, Alan, Greg Shelley, Allan Mazur, Gerry Tharp and Roger Kittok. 1989. "Testosterone and Winning and Losing in Human Competition." Hormones and Behavior. 23: 556-571.

Carre, Justin M., Jenna D. Gilchrist, Mark D. Morrissey, Cheryl M. McCormick. 2010. "Motivational and Situational Factors and the Relationship Between Testosterone Dynamics and Human Aggression During Competition." Biological Psychology. 84 (2): 346-353.

Carre Justin M. and Cheryl M. McCormick. 2008. "Aggressive Behavior and Change in Salivary Testosterone Concentrations Predict Willingness to Engage in a Competitive Task." Hormones and Behavior. 54 (3): 403-409.

Coates, John. 2012. “The Hour between Dog and Wolf: How Risk-Taking Transforms Us, Body and Mind.” Penguin USA; Random House Canada; Fourth Estate UK.

Coates, John M., Mark Gurnell and Aldo Rustichini. 2009. "Second-to-Fourth Digit Ratio Predicts Success among High-Frequency Financial Traders.” Proceedings of the National Academy of Sciences. 106 (2): 623-628. 
Coates, John M., Mark Gurnell and Zoltan Sarnyai. 2010. "From Molecule to Market: Steroid Hormones and Financial Risk-Taking." Philosophical Transactions of the Royal Society of London B: Biological Sciences. 365 (1538): 331-343.

Coates, John M., and Joe Herbert. 2008. "Endogenous Steroids and Financial Risk Taking on a London Trading Floor." Proceedings of the National Academy of Sciences. 105 (16): 6167-6172.

Cueva, Carlos, R. Edward Roberts, Tom Spencer, Nisha Rani, Michelle Tempest, Philippe N. Tobler, Joe Herbert, and Aldo Rustichini. 2015. "Cortisol and Testosterone Increase Financial Risk Taking and May Destabilize Markets." Scientific Reports. 5.

Eckel, Catherine C. and Sascha Füllbrunn. 2015. "Thar 'She' Blows? Gender, Competition, and Bubbles in Experimental Asset Markets." American Economic Review. 105 (2): 906920.

Edwards, David A. and Lauren S. Kurlander. 2010. "Women's Intercollegiate Volleyball and Tennis: Effects of Warm-up, Competition, and Practice on Saliva Levels of Cortisol and Testosterone." Hormones and Behavior. 58 (4): 606-613.

Edwards, David A., Karen Wetzel and Dana R. Wyner. 2006. "Intercollegiate Soccer: Saliva Cortisol and Testosterone are Elevated During Competition, and Testosterone is Related to Status and Social Connectedness with Team Mates." Physiology and Behavior. 87 (1): 135-143.

Elias, Michael. 1981. "Serum Cortisol, Testosterone, and Testosterone-Binding Globulin Responses to Competitive Fighting in Human Males." Aggressive Behavior. 7: 215-224.

Fama, Eugene and Kenneth French. 2012. "Size, Value, and Momentum in International Stock Returns." Journal of Financial Economics. 105 (3): 457-472.

Gladue, Brian A., Michael Boechler and Kevin D. McCaul. 1989. "Hormonal Response to Competition in Human Males." Aggressive Behavior. 15 (6): 409-422

Groh, Christian, Benny Moldovanu, Aner Sela and Uwe Sunde. 2012. "Optimal Seedings in Elimination Tournaments." Economic Theory. 49: 59-80. 
Iso-Ahola, Seppo and Ken Mobily. 1980. "Psychological Momentum: A Phenomenon and an Empirical (Unobtrusive) Validation of Its Influence in a Competitive Sport Tournament." Psychological Reports. 46: 391-401.

Kahneman, Daniel and Amos Tversky. 1979. "Prospect Theory: An Analysis of Decision under Risk." Econometrica. 47 (2): 263-291.

Klumpp, Tilman and Mattias Polborn. 2006. "Primaries and the New Hampshire Effect." Journal of Public Economics. 90: 1073-1114

Kocher, Martin, Marc Lenz and Matthias Sutter. 2012. "Psychological Pressure in Competitive Environments: New Evidence from Randomized Natural Experiments." Management Science. 58 (8): 1585-1591.

Krumer, Alex. 2014. "On Winning Probabilities, Weight Categories and Home Advantage in Professional Judo." Journal of Sports Economics. forthcoming.

Lazear, Edward and Sherwin Rosen. 1981. "Rank Order Tournaments as Optimal Labor Contracts." Journal of Political Economy. 89 (5): 841-864.

Mago, Shakun, Roman Sheremeta and Andrew Yates. 2013. "Best-of-Three Contest Experiments: Strategic versus Psychological Momentum." International Journal of Industrial Organization. 31 (3): 287-296.

Malueg, David and Andrew Yates. 2010. "Testing Contest Theory: Evidence from Best-ofThree Tennis Matches." The Review of Economics and Statistics. 92 (3): 689-692.

Mazur, Allan, Alan Booth, and James M. Dabbs Jr. 1992. "Testosterone and Chess Competition." Social Psychology Quarterly. 55 (1): 70-77.

Mazur, Allan. 1985. "A Biosocial Model of Status in Face-to-Face Primate Groups." Social Forces. 64 (2): 377-402.

Mazur Allan. 1995. "Biosocial Models of Deviant Behavior among Male Army Veterans." Biological Psychology. 41 (3): 271-293.

McCaul, Kevin D., Brian A. Gladue and Margaret Joppa. 1992. "Winning, Losing, Mood, and Testosterone." Hormones and Behavior. 26 (4): 486-504. 
Oyegbile Temitayo O. and Catherine A. Marler. 2005. "Winning Fights Elevates Testosterone Levels in California Mice and Enhances Future Ability to Win Fights." Hormones and Behavior. 48 (3): 259-267.

Rosen, Sherwin. 1986. "Prizes and Incentives in Elimination Tournaments." The American Economic Review. 76 (4): 701-715.

Salvador, Alicia, Ferran Suay, Gonzalez Bono and Miguel A. Serrano. 2003. "Anticipatory Cortisol, Testosterone and Psychological Responses to Judo Competition in Young Men." Psychoneuroendocrinology. 28 (3): 364-375.

Stanton, Steven J., Scott H. Liening and Oliver C. Schultheiss. 2011. "Testosterone is Positively Associated with Risk Taking in the Iowa Gambling Task." Hormones and Behavior. 59 (2): 252-256.

Suay, Ferran, et al. 1999. "Effects of Competition and Its Outcome on Serum Testosterone, Cortisol and Prolactin. Psychoneuroendocrinology, 24 (5): 551-566.

Trainor, Brian C., Ian M. Bird, and Catherine A. Marler. 2004. "Opposing Hormonal Mechanisms of Aggression Revealed Through Short-lived Testosterone Manipulations and Multiple Winning Experiences." Hormones and Behavior. 45 (2): 115-121.

van Honk, Jack, et al. 2004. "Testosterone Shifts the Balance between Sensitivity for Punishment and Reward in Healthy Young Women." Psychoneuroendocrinology. 29 (7): 937-943.

Wood, Ruth I., and Steven J. Stanton. 2012. "Testosterone and Sport: Current Perspectives." Hormones and behavior. 61 (1): 147-155. 
Figure 1 : Competition Structure
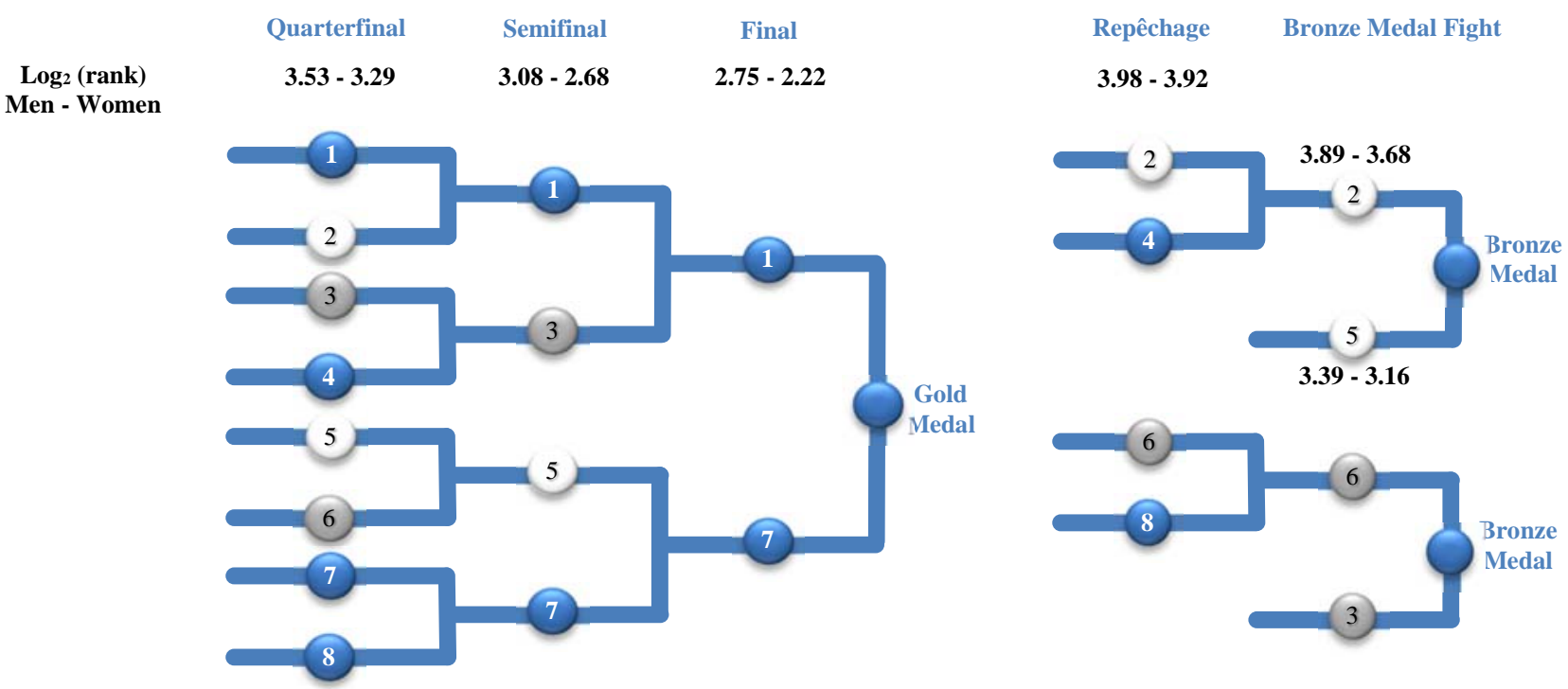

Figure 2: Suggestion for a New Contest Design for Bronze Medal Fights

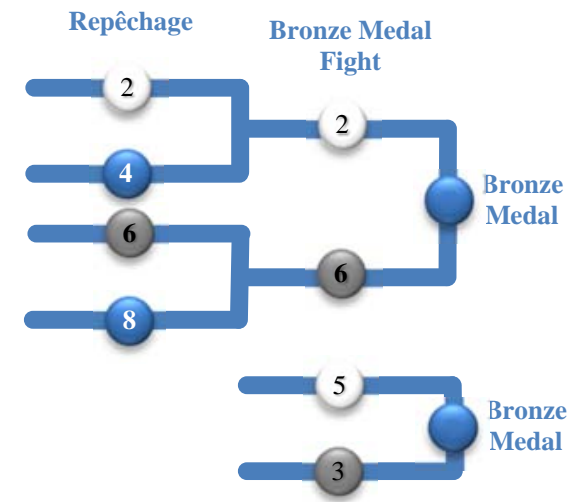


Table 1: Descriptive Statistics of Dataset A

\begin{tabular}{|c|c|c|c|c|c|c|}
\hline \multirow[t]{2}{*}{ Variable } & \multicolumn{2}{|c|}{$\begin{array}{l}\text { General Sample: } \\
(\mathrm{N}=3,624)\end{array}$} & \multicolumn{2}{|c|}{$\begin{array}{l}\text { Men Only } \\
(\mathrm{N}=2,140)\end{array}$} & \multicolumn{2}{|c|}{$\begin{array}{l}\text { Women Only } \\
(\mathrm{N}=1,484)\end{array}$} \\
\hline & Mean & $\begin{array}{l}\text { Standard } \\
\text { deviation }\end{array}$ & Mean & $\begin{array}{l}\text { Standard } \\
\text { deviation }\end{array}$ & Mean & $\begin{array}{r}\text { Standard } \\
\text { deviation }\end{array}$ \\
\hline Favorite won & 0.697 & 0.459 & 0.700 & 0.459 & 0.694 & 0.461 \\
\hline Favorite has momentum advantage (FMA) & 0.023 & 0.150 & 0.021 & 0.142 & 0.027 & 0.162 \\
\hline Underdog has momentum advantage (UMA) & 0.037 & 0.188 & 0.029 & 0.168 & 0.048 & 0.214 \\
\hline Women & 0.409 & 0.492 & & & & \\
\hline \multicolumn{7}{|l|}{ Basic controls } \\
\hline $\begin{array}{l}\text { Past head-to-head favorite advantage (wins- } \\
\text { losses) }\end{array}$ & 0.225 & 0.910 & 0.178 & 0.775 & 0.292 & 1.073 \\
\hline Rank difference ( $\log _{2}\left(\right.$ RankF)- $\log _{2}($ RankU) & -2.015 & 1.455 & -2.035 & 1.464 & -1.985 & 1.442 \\
\hline Favorite home advantage & 0.091 & 0.288 & 0.088 & 0.283 & 0.096 & 0.295 \\
\hline Underdog home advantage & 0.078 & 0.268 & 0.078 & 0.268 & 0.077 & 0.267 \\
\hline \multicolumn{7}{|l|}{ Weight categories } \\
\hline $60 \mathrm{~kg}$ & 0.084 & 0.277 & 0.142 & 0.349 & & \\
\hline 66 kg & 0.087 & 0.281 & 0.147 & 0.354 & & \\
\hline 73 kg & 0.101 & 0.302 & 0.171 & 0.377 & & \\
\hline $81 \mathrm{~kg}$ & 0.097 & 0.296 & 0.164 & 0.370 & & \\
\hline 90 kg & 0.081 & 0.273 & 0.137 & 0.344 & & \\
\hline 100 kg & 0.075 & 0.264 & 0.128 & 0.334 & & \\
\hline More than $100 \mathrm{~kg}$ & 0.066 & 0.248 & 0.111 & 0.314 & & \\
\hline $48 \mathrm{~kg}$ & 0.055 & 0.228 & & & 0.134 & 0.341 \\
\hline 52 kg & 0.065 & 0.247 & & & 0.160 & 0.366 \\
\hline 57 kg & 0.068 & 0.252 & & & 0.166 & 0.372 \\
\hline $63 \mathrm{~kg}$ & 0.068 & 0.252 & & & 0.166 & 0.373 \\
\hline 70 kg & 0.057 & 0.233 & & & 0.140 & 0.347 \\
\hline 78 kg & 0.050 & 0.219 & & & 0.123 & 0.329 \\
\hline More than 78 kg & 0.045 & 0.208 & & & 0.111 & 0.314 \\
\hline \multicolumn{7}{|l|}{ Stage of the tournament categories } \\
\hline Stage of best 128 & 0.036 & 0.185 & 0.060 & 0.237 & 0.001 & 0.026 \\
\hline Stage of best 64 & 0.180 & 0.384 & 0.215 & 0.411 & 0.129 & 0.335 \\
\hline Stage of best 32 & 0.246 & 0.431 & 0.256 & 0.436 & 0.233 & 0.423 \\
\hline Stage of best 16 & 0.209 & 0.406 & 0.191 & 0.393 & 0.235 & 0.424 \\
\hline Quarterfinal stage & 0.122 & 0.327 & 0.104 & 0.305 & 0.148 & 0.355 \\
\hline Repêchage stage & 0.057 & 0.231 & 0.049 & 0.215 & 0.068 & 0.252 \\
\hline Semifinal stage & 0.061 & 0.240 & 0.052 & 0.222 & 0.075 & 0.263 \\
\hline Bronze medal stage & 0.060 & 0.237 & 0.050 & 0.217 & 0.075 & 0.263 \\
\hline Final stage & 0.030 & 0.172 & 0.025 & 0.157 & 0.038 & 0.191 \\
\hline \multicolumn{7}{|l|}{ Tournament type categories } \\
\hline Olympic Games & 0.116 & 0.320 & 0.116 & 0.321 & 0.115 & 0.319 \\
\hline World Championships & 0.582 & 0.493 & 0.584 & 0.493 & 0.578 & 0.494 \\
\hline Grand Slam & 0.239 & 0.427 & 0.243 & 0.429 & 0.232 & 0.423 \\
\hline Masters & 0.064 & 0.244 & 0.056 & 0.230 & 0.075 & 0.263 \\
\hline
\end{tabular}


Table 2: Descriptive Statistics of Dataset B

\begin{tabular}{|c|c|c|c|c|c|c|}
\hline \multirow[t]{2}{*}{ Variable } & \multicolumn{2}{|c|}{$\begin{array}{c}\text { General sample: } \\
(\mathrm{N}=456)\end{array}$} & \multicolumn{2}{|c|}{$\begin{array}{c}\text { Men Only } \\
(\mathrm{N}=225)\end{array}$} & \multicolumn{2}{|c|}{$\begin{array}{l}\text { Women Only } \\
(\mathrm{N}=231)\end{array}$} \\
\hline & Mean & $\begin{array}{l}\text { Standard } \\
\text { deviation }\end{array}$ & Mean & $\begin{array}{l}\text { Standard } \\
\text { deviation }\end{array}$ & Mean & $\begin{array}{l}\text { Standard } \\
\text { deviation }\end{array}$ \\
\hline Player $i$ won & 0.485 & 0.500 & 0.480 & 0.501 & 0.489 & 0.501 \\
\hline Momentum Index (MI) & -0.004 & 0.702 & -0.036 & 0.700 & 0.026 & 0.704 \\
\hline Women & 0.507 & 0.501 & & & & \\
\hline \multicolumn{7}{|l|}{$\begin{array}{r}\text { Basic controls } \\
\end{array}$} \\
\hline $\begin{array}{l}\text { Past head-to-head player i's advantage } \\
\text { (Player i's wins -losses) }\end{array}$ & 0.050 & 1.282 & 0.093 & 1.304 & 0.009 & 1.261 \\
\hline Rank difference ( $\log _{2}\left(\right.$ Ranki)- $\log _{2}($ Rankj) & 0.086 & 2.078 & 0.047 & 2.109 & 0.124 & 2.051 \\
\hline Player $i$ has home advantage & 0.121 & 0.326 & 0.138 & 0.345 & 0.104 & 0.306 \\
\hline Player $j$ has home advantage & 0.079 & 0.270 & 0.084 & 0.279 & 0.074 & 0.262 \\
\hline \multicolumn{7}{|l|}{ Stage of the tournament categories } \\
\hline Bronze medal stage & 0.491 & 0.500 & 0.489 & 0.501 & 0.494 & 0.501 \\
\hline Stage of best 16 & 0.143 & 0.350 & 0.147 & 0.355 & 0.139 & 0.346 \\
\hline Stage of best 32 & 0.033 & 0.179 & 0.022 & 0.148 & 0.043 & 0.204 \\
\hline Quarterfinal stage & 0.121 & 0.326 & 0.107 & 0.309 & 0.134 & 0.342 \\
\hline Semifinal stage & 0.134 & 0.341 & 0.160 & 0.367 & 0.108 & 0.311 \\
\hline Final stage & 0.064 & 0.244 & 0.067 & 0.250 & 0.061 & 0.239 \\
\hline Repêchage stage & 0.015 & 0.123 & 0.009 & 0.094 & 0.022 & 0.146 \\
\hline \multicolumn{7}{|l|}{ Tournament type categories } \\
\hline Asia Championships & 0.004 & 0.066 & 0.004 & 0.067 & 0.004 & 0.066 \\
\hline European Open & 0.004 & 0.066 & & & 0.009 & 0.093 \\
\hline European Championships & 0.053 & 0.224 & 0.031 & 0.174 & 0.074 & 0.262 \\
\hline Grand Prix & 0.092 & 0.289 & 0.102 & 0.304 & 0.082 & 0.275 \\
\hline Grand Slam & 0.340 & 0.474 & 0.356 & 0.480 & 0.325 & 0.469 \\
\hline Masters & 0.114 & 0.318 & 0.107 & 0.309 & 0.121 & 0.327 \\
\hline Olympic Games & 0.079 & 0.270 & 0.084 & 0.279 & 0.074 & 0.262 \\
\hline Pan American Championships & 0.002 & 0.047 & & & 0.004 & 0.066 \\
\hline World Championships & 0.239 & 0.427 & 0.240 & 0.428 & 0.238 & 0.427 \\
\hline World Cup & 0.072 & 0.259 & 0.076 & 0.265 & 0.069 & 0.254 \\
\hline
\end{tabular}


Table 3: Logit Average Marginal Effects of Momentum Variables on the Probability of the Favorite to Win the Fight

\begin{tabular}{|c|c|c|c|c|c|c|c|c|}
\hline \multirow{3}{*}{ Variable } & \multicolumn{3}{|c|}{ All Data } & \multicolumn{5}{|c|}{ Bronze Medal Fights } \\
\hline & $(1)$ & $(2)$ & (3) & $(4)$ & $(5)$ & $(6)$ & $(7)$ & $(8)$ \\
\hline & \multicolumn{8}{|c|}{ Panel A: Men } \\
\hline Favorite has momentum advantage & $\begin{array}{c}0.041 \\
(0.069)\end{array}$ & $\begin{array}{c}0.052 \\
(0.068)\end{array}$ & $\begin{array}{l}0.178^{* *} \\
(0.086)\end{array}$ & $\begin{array}{c}0.176^{* *} \\
(0.089)\end{array}$ & $\begin{array}{l}0.160 * \\
(0.096)\end{array}$ & $\begin{array}{c}0.223^{* *} \\
(0.095)\end{array}$ & $\begin{array}{l}0.183^{*} \\
(0.103)\end{array}$ & $\begin{array}{c}0.356^{* *} \\
(0.159)\end{array}$ \\
\hline Underdog has momentum advantage & $\begin{array}{c}-0.138^{* *} \\
(0.055)\end{array}$ & $\begin{array}{c}-0.131 * * \\
(0.056)\end{array}$ & & & & & & \\
\hline Dummy for bronze medal fight & & & $\begin{array}{l}-0.125 \\
(0.077)\end{array}$ & & & & & \\
\hline Observations & 2140 & 2140 & 2140 & 106 & 106 & 99 & 99 & 47 \\
\hline \multirow{2}{*}{ Pseudo R-squared } & 0.072 & 0.077 & 0.085 & 0.057 & 0.105 & 0.077 & 0.134 & 0.439 \\
\hline & \multicolumn{8}{|c|}{ Panel B: Women } \\
\hline Favorite has momentum advantage & $\begin{array}{c}-0.113^{*} \\
(0.069)\end{array}$ & $\begin{array}{l}-0.106 \\
(0.069)\end{array}$ & $\begin{array}{c}-0.086 \\
(0.085)\end{array}$ & $\begin{array}{c}-0.068 \\
(0.093)\end{array}$ & $\begin{array}{c}-0.073 \\
(0.088)\end{array}$ & $\begin{array}{l}-0.077 \\
(0.109)\end{array}$ & $\begin{array}{l}-0.072 \\
(0.103)\end{array}$ & $\begin{array}{l}-0.073 \\
(0.171)\end{array}$ \\
\hline Underdog has momentum advantage & $\begin{array}{l}-0.032 \\
(0.053)\end{array}$ & $\begin{array}{c}-0.015 \\
(0.054)\end{array}$ & & & & & & \\
\hline Dummy for bronze medal fight & & & $\begin{array}{c}0.096 \\
(0.074)\end{array}$ & & & & & \\
\hline Observations & 1484 & 1484 & 1484 & 111 & 111 & 97 & 97 & 43 \\
\hline \multirow[t]{2}{*}{ Pseudo R-squared } & 0.086 & 0.093 & 0.101 & 0.062 & 0.120 & 0.072 & 0.146 & 0.306 \\
\hline & \multicolumn{8}{|c|}{ Panel C: Comparison between men and women (P-value) } \\
\hline Favorite has momentum advantage & 0.056 & 0.052 & 0.015 & 0.034 & 0.040 & 0.023 & 0.045 & 0.034 \\
\hline Underdog has momentum advantage & 0.085 & 0.070 & & & & & & \\
\hline Basic controls & $\mathrm{Y}$ & $\mathrm{Y}$ & $\bar{Y}$ & $\mathrm{Y}$ & $\mathrm{Y}$ & $\mathrm{Y}$ & $\bar{Y}$ & $\bar{Y}$ \\
\hline Tournament type fixed effects (TTFE) & $\mathrm{N}$ & $\mathrm{Y}$ & $\mathrm{Y}$ & $\mathrm{N}$ & $\mathrm{Y}$ & $\mathrm{N}$ & $\mathrm{Y}$ & $\mathrm{Y}$ \\
\hline Weight fixed effects & $\mathrm{N}$ & $\mathrm{Y}$ & $\mathrm{Y}$ & $\mathrm{N}$ & $\mathrm{Y}$ & $\mathrm{N}$ & $\mathrm{Y}$ & $\mathrm{Y}$ \\
\hline Stage fixed effects (SFE) & $\mathrm{N}$ & $\mathrm{N}$ & $\mathrm{Y}$ & $\mathrm{N}$ & $\mathrm{N}$ & $\mathrm{N}$ & $\mathrm{N}$ & $\mathrm{N}$ \\
\hline Selection controls & $\mathrm{N}$ & $\mathrm{N}$ & $\mathrm{N}$ & $\mathrm{N}$ & $\mathrm{N}$ & $\mathrm{Y}$ & $\mathrm{Y}$ & $\mathrm{Y}$ \\
\hline
\end{tabular}

Notes: Our list of basic controls includes the $R A N K D I F F_{i j w t}$, dummy variables for whether each of the players has a home advantage, and the past head-to-head favorite advantage (number of favorite wins minus number of favorite losses). Robust standard errors are reported in parentheses. * significant at $10 \%,{ }^{* *}$ significant at $5 \%$, *** significant at $1 \%$. 
Table 4:

The Relationship between Momentum and Characteristics

\begin{tabular}{|l|c|c|}
\hline & Men & Women \\
\hline & $(1)$ & $(2)$ \\
\hline Ranking difference & 0.391 & 0.096 \\
& $(0.250)$ & $(0.265)$ \\
\hline \multirow{2}{*}{ Head-To-Head } & -0.312 & 0.306 \\
& $(0.213)$ & $(0.243)$ \\
\hline \multirow{2}{*}{ First player home advantage } & 0.010 & 0.044 \\
& $0.056)$ & $0.055)$ \\
\hline \multirow{2}{*}{ Second player home advantage } & 0.030 & -0.049 \\
& $(0.070)$ & $(0.050)$ \\
\hline \hline
\end{tabular}

* significant at $10 \%, * *$ significant at $5 \%, * * *$ significant at $1 \%$.

Table 5: FE Estimates of the Effect of Momentum Advantage on the Probability to Win a Fight

\begin{tabular}{|l|cccccc|}
\hline \hline & & \multicolumn{3}{c}{ Men } & & \multicolumn{4}{c|}{ Women } \\
\cline { 5 - 8 } & Basic & TTFE+SFE & $\begin{array}{c}\text { Head- } \\
\text { To-Head }\end{array}$ & Basic & TTFE+SFE & Head-To-Head \\
& $(1)$ & $(2)$ & $(3)$ & $(4)$ & $(5)$ & $(6)$ \\
\hline Momentum Index & $0.177^{* *}$ & $0.185^{* * *}$ & $0.111^{*}$ & 0.079 & 0.080 & 0.095 \\
& $(0.070)$ & $(0.073)$ & $(0.061)$ & $(0.078)$ & $(0.079)$ & $(0.064)$ \\
\hline Observations & 225 & 225 & 225 & 231 & 231 & 231 \\
Num. of obs. Outside & 0 & 0 & 24 & 0 & 0 & 37 \\
range 0-1 & 104 & 104 & 104 & 109 & 109 & 109 \\
$\begin{array}{l}\text { Number of “pairs" } \\
\text { R-squared }\end{array}$ & 0.066 & 0.102 & 0.287 & 0.013 & 0.106 & 0.257 \\
\hline \hline
\end{tabular}

Notes: Our list of basic controls includes the RANKDIFF $i j w$ and dummy variables for whether each of the contestants has a home advantage. In Columns 2 and 5, TTFE and SFE denote tournament type fixed effects and stage in tournament fixed effects, respectively. Robust standard errors are reported in parentheses.

* significant at $10 \%, * *$ significant at $5 \%, * * *$ significant at $1 \%$. 